\title{
EGTA treatment of human airways in vitro unmasks M1/MUC5AC mucin in submucosal glands
}

\author{
P. Roger*, J-P. Gascard*, J. Bara\# ${ }^{\#}$ E. Dulmet ${ }^{\Uparrow}$, C. Brink*
}

EGTA treatment of human airways in vitro unmasks M1/MUC5AC mucin in submucosal glands. P. Roger, J-P. Gascard, J. Bara, E. Dulmet, C. Brink. (C)ERS Journals Ltd 2001.

ABSTRACT: Mucin staining can be used to evaluate secretory activity of human airways. However, mucin epitopes may be masked by physicochemical properties of the secretions. The aim of this investigation was to examine the effects of the calcium chelator, ethyleneglycol-bis-( $\beta$-aminoethylether)-N, N, N', N'-tetraacetic acid (EGTA) on the detection of M1/MUC5AC mucin in isolated human bronchial preparations.

Immunohistochemical investigation and immunoradiometric assays with anti-M1 monoclonal antibodies (Mabs) were used to detect M1/MUC5AC mucin derived from bronchial preparations with an intact surface epithelium, or in tissues where the epithelium had been removed (rubbed preparations).

The Mabs labelled both epithelial goblet cells and submucosal glandular cells in EGTA (4 mM)-exposed bronchial preparations, while only goblet cells were stained in EGTA $(0.4 \mathrm{mM})$-exposed tissues. The quantities of M1/MUC5AC mucin detected in either the bronchial fluids derived from EGTA $(4 \mathrm{mM})$-exposed intact and rubbed preparations or in bronchial fluids treated with EGTA $(4 \mathrm{mM})$ were significantly increased by two-fold when compared with untreated control values $(p<0.001)$. In addition, lactate dehydrogenase (LDH) activity and protein measurements were unaltered during exposure of human airways to EGTA $(4 \mathrm{mM})$ suggesting that this treatment did not affect tissue viability.

These results provide evidence that ethyleneglycol-bis-( $\beta$-aminoethylether)- $N, N, N^{\prime}$, $\mathrm{N}^{\prime}$-tetraacetic acid (4 mM) facilitates the detection of M1/MUC5AC mucin by altering the physicochemical properties of respiratory mucin, thereby exposing epitopes with which anti-M1 monoclonal antibodies are reactive. This will allow more accurate measurement of secretory activity in human airways in vitro. Eur Respir J 2001; 18: 176-183.
*Laboratoire de Pharmacologie Pulmonaire and "Laboratoire d'Anatomopathologie, Hôpital Marie Lannelongue, Le Plessis Robinson, France and ${ }^{\#}$ INSERM U 482, Hôpital Saint Antoine, Paris, France.

Correspondence: C. Brink, CNRS-ESA 8078, Laboratory of Pulmonary Pharmacology, Hôpital Marie Lannelongue, 133 Av de la Résistance, 92350 Le Plessis Robinson, France.

Fax: 330146301208

Keywords: EGTA

glands

goblet cells

human airways

M1/MUC5AC mucin

Received: December 202000

Accepted after revision March 282001
In canine tracheal preparations, MARIN et al. [1] demonstrated a marked reduction in sulphate uptake when tissues were exposed to calcium depleted media. However, these investigators reported that the release of sulphate incorporated into mucin glycoprotein was independent of calcium ions $\left(\mathrm{Ca}^{2+}\right)$ in the media. Other studies demonstrated that incubation of tracheal cells in $\mathrm{Ca}^{2+}$-free media induced a timedependent increase in baseline release of mucin glycoproteins [2, 3]. In addition, either an increase or decrease of $\mathrm{Ca}^{2+}$ concentrations in the media augmented the secretion of mucins from isolated chicken tracheae [4]. These data suggested that the secretory activity of mucins from tracheal cells was dependent on $\mathrm{Ca}^{2+}$. Coles et al. [5] suggested that depletion of $\mathrm{Ca}^{2+}$ by chelation with ethyleneglycolbis-( $\beta$-aminoethylether)-N, N, N', N'-tetraacetic acid (EGTA) not only increased the quantities of glycoproteins released from canine airways, but also modified the physical properties of the mucus released from glandular cells by altering the solubility. Such results were in accordance with previous reports demonstrating that variations of $\mathrm{Ca}^{2+}$ concentrations or addition of cation chelators to media, induced changes in the rheological and physical properties of mucins [6-8]. In these latter studies, the secretion of mucin from tracheae after EGTA exposure was monitored by incorporation of radiolabels into secreting cells, and little information concerning the nature of the glycoproteins released was provided. M1/MUC5AC mucins have been previously detected with an immunoradiometric assay (IRMA) using a mixture of eight anti-M1 monoclonal antibodies (Mabs) $[9,10]$ specifically raised against the peptidic core of M1 mucins and having high affinity for an M1 mucin partially encoded by the MUC5AC gene [11]. Recently, these Mabs have also been used to evaluate secretory activity in human airways [12-14].

The aim of this study was to examine whether the calcium chelator EGTA facilitated the detection of M1/MUC5AC mucin in human airways. In addition, in order to preclude any effects of EGTA on the 
viability of human airways during the EGTA exposure, a measure of lactate dehydrogenase (LDH) and protein secretion was also performed.

\section{Material and methods}

\section{Source of chemicals and material}

Phosphate buffered saline (PBS) tablets, bovine serum albumin (BSA), Tween 20, horseradish peroxidase conjugated antimouse immunoglobulin-G (IgG), and EGTA were purchased from Sigma Chemical Co. (St. Louis, MO, USA). Pronase E was a product from Calbiochem (France Biochem, France). Polystyrene stars and tubes were obtained from $\mathrm{Cis}$ Bio Industrie (Saint Quentin en Yvelines, France). The LSAB-2 kit for immunolabelling was obtained from Dako Laboratories (Carpinteria, CA, USA). The LDH assay was performed using Biotrol Diagnostic Societe Francaise de Biologie Clinique (SFBC) kits (Chennevrièresles-Louvres, France).

\section{M1 mucin standard and monoclonal antibodies}

M1 mucins isolated from an ovarian mucinous cyst fluid were used as standard. Eight Mabs raised against epitopes associated with the peptide core of M1 mucins, permitted the detection of mucins $[9,10]$. These anti-M1 mucin Mabs are $\operatorname{IgG}_{1}$. Immunohistochemical analysis was performed using either the 1-13 M1 or 21 M1 Mabs alone, or a mixture of eight anti-M1 mucin Mabs (PM8) which included both the 1-13 M1 and 21 M1 Mabs. IRMA experiments were performed using the individual $21 \mathrm{M} 1$ and PM8 Mabs.

\section{Tissues}

Human lung tissues were obtained from patients who had undergone surgery for lung carcinoma. Tissues were obtained from the resected lung at a distance from the tumour area. Subsequently, the bronchi (third to sixth generation bronchi) were dissected free from the parenchyma tissue and washed with a physiological Tyrode's solution containing: $\mathrm{NaCl}(139.2 \mathrm{mM}), \mathrm{KCl}(2.7 \mathrm{mM}), \mathrm{CaCl}_{2}$ (1.8 mM), $\mathrm{MgCl}_{2}(1.04 \mathrm{mM}), \mathrm{NaHCO}_{3}(11.9 \mathrm{mM})$, $\mathrm{NaH}_{2} \mathrm{PO}_{4}(0.4 \mathrm{mM})$ and glucose $(5.5 \mathrm{mM}), \mathrm{pH}$ 7.4. Bronchial tissues were cut as rings $(4-7 \mathrm{~mm}$, internal diameter and 100-225 mg, wet weight). Bronchial preparations with or without surface epithelium were examined. The surface epithelium was removed by gently rubbing the luminal surface of the bronchial rings with a moistened cotton swab.

\section{Immunohistochemical analysis}

Subsequent to a 60-min incubation in the absence or presence of EGTA $(0.4$ or $4 \mathrm{mM})$, human bronchial rings were fixed in formalin for $12 \mathrm{~h}$, dehydrated, embedded in paraffin and sections $(5 \mu \mathrm{m})$ were cut.
Tissue deparaffinized sections were rinsed in PBS (10 mM, pH 7.4 containing Tween $20(0.1 \%)$ ). Sections were then treated with pronase E $(0.025 \%)$ in $0.05 \mathrm{M}$ Tris-HC1 buffer, $\mathrm{pH} 7.6$ for $7 \mathrm{~min}$ at room temperature to unmask the mucin epitopes [15]. After several washes of sections in PBS-Tween $20(0.1 \%)$, endogenous peroxidases were eliminated with $\mathrm{H}_{2} \mathrm{O}_{2}$ $(3 \%)$ in methanol for $5 \mathrm{~min}$. Tissue sections were incubated in PBS-Tween $20(0.1 \%)$ containing BSA $(1 \%)$ for $5 \mathrm{~min}$ at room temperature and then incubated with the 1-13 M1 and 21 M1 Mabs at the final concentration of $10 \mu \mathrm{g} \cdot \mathrm{mL}^{-1}$ in PBS-Tween 20 $(0.1 \%)$. Sections from the same lung samples were also incubated in the presence of PM8 Mabs in PBS-BSA $(1 \%)$ for $1 \mathrm{~h}$. After several washes with PBS-Tween 20 $(0.1 \%)$, tissue sections were incubated with horseradish peroxidase conjugated antimouse $\mathrm{IgG}$ diluted at 1:50 in PBS for $1 \mathrm{~h}$ at room temperature. The peroxidase activity was revealed using the diaminobenzidine $/ \mathrm{H}_{2} \mathrm{O}_{2}$ revelation system as described in the LSAB-2 kit, in the dark for $10 \mathrm{~min}$ and tissues sections were counter-stained $(2 \mathrm{~min})$ with Harris haematoxylin.

\section{Treatment of human bronchial preparations}

Intact and rubbed human bronchial preparations were set up in a microtitre plate ( 24 wells) containing Tyrode's solution $(1 \mathrm{~mL})$ and allowed to equilibrate for $1 \mathrm{~h}$ at $37^{\circ} \mathrm{C}$ in a humidified incubator $(5 \%$ carbon dioxide $\left(\mathrm{CO}_{2}\right) /$ air $)$. At the end of this equilibration period, the medium was exchanged and fresh Tyrode's solution previously warmed at $37^{\circ} \mathrm{C}$ was added for $1 \mathrm{~h}$. Bronchial fluids containing the human secretory mucins (Period I; basal release) were collected. Bronchial rings were then exposed to Tyrode's solution containing EGTA at either $0.4 \mathrm{mM}$ or $4 \mathrm{mM}$ (final concentration). Following $1 \mathrm{~h}$ incubation of the human preparations under these conditions, bronchial fluids were collected (Period II; exposure). The bronchial fluids from Period I and Period II were stored at $-20^{\circ} \mathrm{C}$ and analysed by IRMA.

Treatment of the bronchial fluids with ethyleneglycolbis-( $\beta$-aminoethylether)- $N, N, N^{\prime}, N^{\prime}$-tetraacetic acid

Bronchial fluids (Period I and Period II) were collected from control human bronchial preparations. Fluids obtained from three preparations from each lung sample at the Period II were thawed and aliquoted. One sample was not treated and used as control (Period II). The other aliquots were treated with either EGTA at $0.4 \mathrm{mM}$ or $4 \mathrm{mM}$ (final concentration) for $1 \mathrm{~h}$ at room temperature before analysis by IRMA.

\section{Immunoradiometric assay}

A solid-phase double-antibody-sandwich IRMA was used as previously described by BARA et al. [16]. Polystyrene stars were coated with the 1-13 M1 Mab 
$\left(10 \mu \mathrm{g} \cdot \mathrm{mL}^{-1}\right.$ in $0.01 \mathrm{M}$ PBS, $\left.\mathrm{pH} 7.4\right)$ by incubating for $2 \mathrm{~h}$ at room temperature, rinsing three times with PBS-Tween $20(0.1 \%)$ and subsequently incubating in PBS-BSA $(1 \%)$ overnight at $37^{\circ} \mathrm{C}$. After several washings, stars were dried at $40^{\circ} \mathrm{C}$ and stored at $4{ }^{\circ} \mathrm{C}$ until used. The M1 mucin standard $\left(10 \mu \mathrm{g} \cdot \mathrm{mL}^{-1}\right)$, as well as human bronchial fluids were serially diluted in PBSTween $20(0.1 \%)$ and $300 \mu \mathrm{L}$ of each dilution was added to the 1-13 M1 Mab-coated stars and incubated overnight at $37^{\circ} \mathrm{C}$. Stars were then washed with PBS-Tween $20(0.1 \%)$ and incubated with PM8 Mabs previously radiolabelled with ${ }^{125} \mathrm{I}\left(4-5 \times 10^{5} \mathrm{cpm} \cdot \mathrm{mL}^{-1}\right)$ overnight at $37^{\circ} \mathrm{C}$. Subsequently, the stars were washed and the radioactivity was measured on a gamma counter (Wizard Model 147005 Evry, France). The concentration of mucin contained in the human bronchial fluids were estimated from the IRMA standard curve obtained with the M1 mucin standard. Mucin concentrations were determined in bronchial fluids derived from six lung samples.

\section{Calculation}

The concentration of M1/MUC5AC mucin detected in the fluids derived from human bronchial preparations by the IRMA are expressed as $\mu \mathrm{g}$ of $\mathrm{M} 1 /$ MUC5AC mucin $\cdot \mathrm{mL}^{-1}$ and were estimated from the ovarian cyst M1 mucin standard curves. All results are presented as mean \pm SEM. Statistical analyses were performed using unpaired t-tests. A p-value of $<0.05$ was taken as an indication of significance.

\section{Lactate dehydrogenase assay}

The release of LDH into the Tyrode's solution bathing the bronchial preparations was assessed by measurement of the variation of absorbance at $340 \mathrm{~nm}$ using the Biotrol LDH SFBC kit. Bronchial fluids collected at Period I and Period II from controland EGTA-challenged bronchial preparations were centrifuged at $3,000 \times g$ for $5 \mathrm{~min}$. An aliquot of $10 \mu \mathrm{l}$ of the centrifuged bronchial fluids and fresh Tyrode's solution containing EGTA at 0.4 and $4 \mathrm{mM}$ were immediately added into the reaction mixture. Reactions were maintained at $30^{\circ} \mathrm{C}$ and the absorbance was read at $340 \mathrm{~nm}$ at $30 \mathrm{~s}$, and then every minute for $2 \mathrm{~min}$. All the values are expressed as Units $\cdot \mathrm{mL}^{-1}$ and are mean \pm SEM of six bronchial fluids derived from three human lung samples. Statistical analyses were performed using unpaired t-tests.

\section{Protein determination}

Determination of total protein concentrations was performed systematically on an aliquot $(100 \mu \mathrm{L})$ taken from human bronchial fluids collected from control and EGTA (4 mM)-exposed bronchial preparations. Total proteins were measured using the procedure of Lowny et al. [17] with BSA as standard.

\section{Results}

\section{Immunohistochemistry}

Although labelling of M1/MUC5AC mucin was observed in the intracellular organelles of epithelial goblet cells and the submucosal glandular cells with the 1-13 M1 and PM8 Mabs (fig. 1) subsequent to a 60-min exposure of isolated human bronchial preparations to EGTA ( $4 \mathrm{mM}$ ), only the intracellular organelles of epithelial goblet cells were labelled with the 21 M1 Mab (fig. 1). The intracellular organelles of goblet cells of the surface epithelium of control bronchial preparations were stained with the PM8 Mabs (fig. 2). In EGTA (0.4 mM)-exposed bronchial tissues, a labelling of the M1/MUC5AC mucin present in the intracellular organelles of goblet cells of the surface epithelium was also detected with the 1-13 M1, 21 M1 and PM8 Mabs (fig. 2). In addition, M1/MUC5AC mucin in contact with cilia at the surface epithelium was stained with these Mabs in both control and EGTA ( 0.4 or $4 \mathrm{mM}$ )-exposed bronchial preparations (figs. 1 and 2).

Exposure of human bronchial preparations with an intact surface epithelium to ethyleneglycol-bis( $\beta$-aminoethylether)- $N, N, N^{\prime}, N^{\prime}$-tetraacetic acid

The basal release of M1/MUC5AC mucin from control human bronchial preparations was $0.32 \pm 0.07 \mu \mathrm{g} \cdot \mathrm{mL}^{-1}$ (Period I, nine bronchial preparations from eight lungs; fig. 3). This value was not significantly altered during the experimental protocol under control conditions (Period II) and after a 60-min exposure of bronchial preparations to EGTA $\left(0.4 \mathrm{mM} ; 0.53 \pm 0.11 \mathrm{M} 1 / \mathrm{MUC} 5 \mathrm{AC}\right.$ mucin $\left(\mu \mathrm{g} \cdot \mathrm{mL}^{-1}\right)$; fig. 3). However, when tissues were exposed to a higher concentration of EGTA ( $4 \mathrm{mM})$, the quantities of M1/ MUC5AC mucin detected in the bronchial fluids were significantly increased (approximately two-fold; $0.82 \pm 0.11 \mathrm{M} 1 / \mathrm{MUC} 5 \mathrm{AC}$ mucin $\left(\mu \mathrm{g} \cdot \mathrm{mL}^{-1}\right)$; fig. 3) when data were compared with the amounts detected in fluids derived from paired control preparations from the same lungs $(0.35 \pm 0.10 \mathrm{M} 1 / \mathrm{MUC} 5 \mathrm{AC}$ mucin $\left(\mu \mathrm{g} \cdot \mathrm{mL}^{-1}\right)$; fig. 3). Although the Tyrode's solution containing EGTA $(4 \mathrm{mM})$ had a $\mathrm{pH}$ of 5.4 , incubation of bronchial preparations in Tyrode's solution adjusted to this acidic $\mathrm{pH}$ did not modify the quantities of M1/ MUC5AC mucin detected in fluids (data not shown).

Exposure of bronchial preparations without the surface epithelium to ethyleneglycol-bis-( $\beta$-aminoethylether $)$ $N, N, N^{\prime}, N^{\prime}$-tetraacetic acid

The quantities of mucin detected in fluids with the PM8 Mabs were not significantly modified when bronchial preparations, in which the surface epithelium had been removed, were exposed to EGTA $\left(0.4 \mathrm{mM} ; 0.68 \pm 0.24 \mathrm{M} 1 / \mathrm{MUC} 5 \mathrm{AC}\right.$ mucin $\left(\mu \mathrm{g} \cdot \mathrm{mL}^{-1}\right)$; fig. 4). However, a significant increase in the quantities of mucin detected with the PM8 Mabs was 

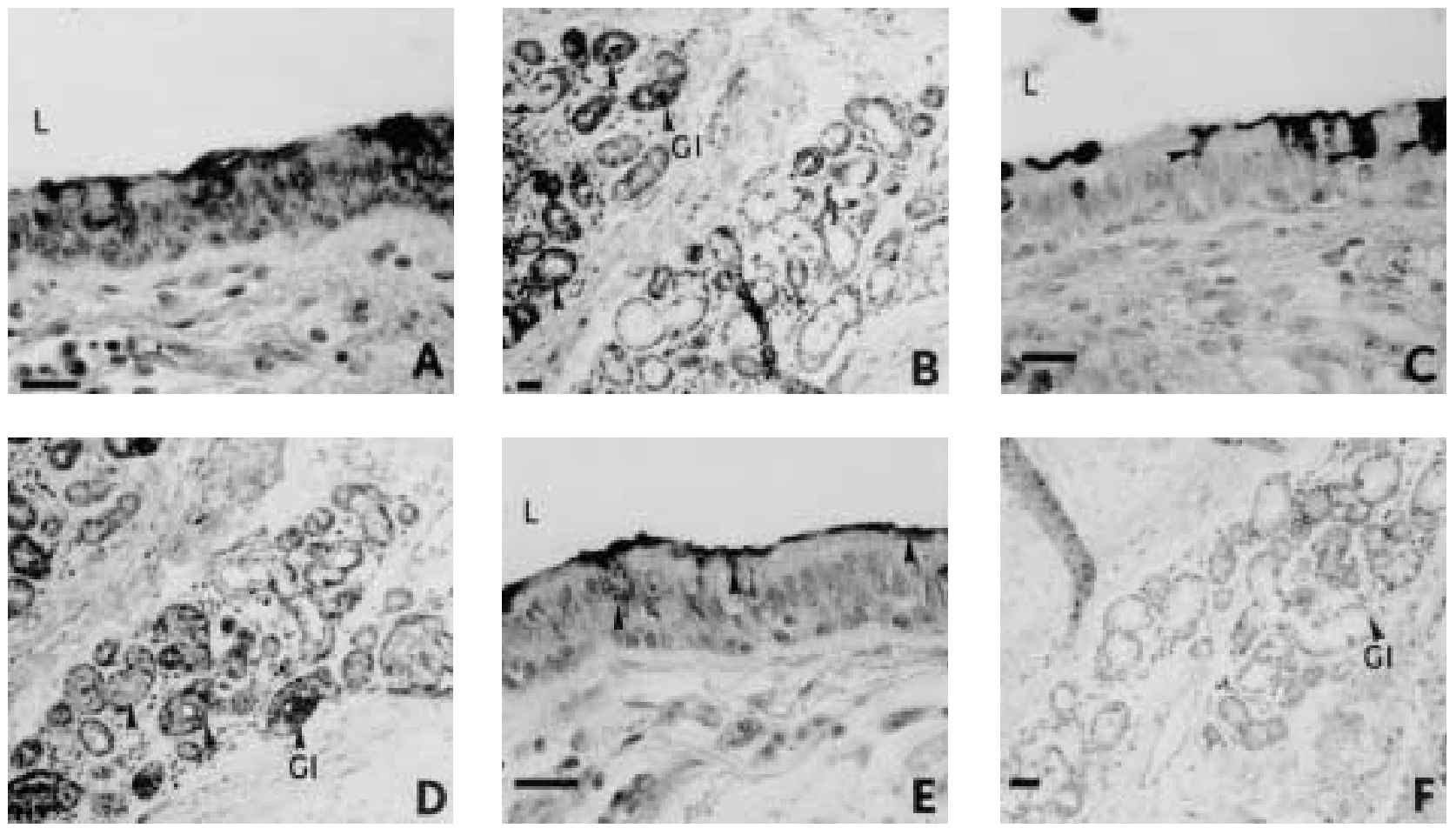

Fig. 1. - Immunohistochemical staining of sections from isolated human bronchial preparations with anti-M1 monoclonal antibodies (Mabs) subsequent to ethyleneglycol-bis-( $\beta$-aminoethylether)-N, N, N', $\mathrm{N}^{\prime}$-tetraacetic acid (EGTA) (4 mM; 60 min) exposure. Labelling of the intracellular organelles of epithelial goblet cells and submucosal glands was observed with the 1-13 M1 (A, B) and PM8 Mabs (C, D). Intracellular organelles of goblet cells of the surface epithelium of bronchial preparations were stained with the $21 \mathrm{M} 1 \mathrm{Mab}(\mathrm{E})$, while no labelling of glands was detected with the $21 \mathrm{M} 1 \mathrm{Mab}(\mathrm{F})$. Internal scale bars $=80 \mu \mathrm{m}(\mathrm{A}, \mathrm{C}, \mathrm{E})$ and $160 \mu \mathrm{m}(\mathrm{B}, \mathrm{D}, \mathrm{F})$. L: lumen of the airway; G1: glandular region; arrows: Mabs labelling and/or glands.

observed in fluids collected from bronchial preparations without the surface epithelium, after a 60 -min exposure to EGTA ( $4 \mathrm{mM} ; 1.24 \pm 0.17 \mathrm{M} 1 / \mathrm{MUC} 5 \mathrm{AC}$ mucin $\left(\mu \mathrm{g} \cdot \mathrm{mL}^{-1}\right)$; fig. 4). When the $21 \mathrm{M} 1 \mathrm{Mab}$ was used to detect the mucin, no modification in the quantities of M1/MUC5AC mucin was observed between controls and EGTA (4 mM)-exposed bronchial preparations (fig. 4).
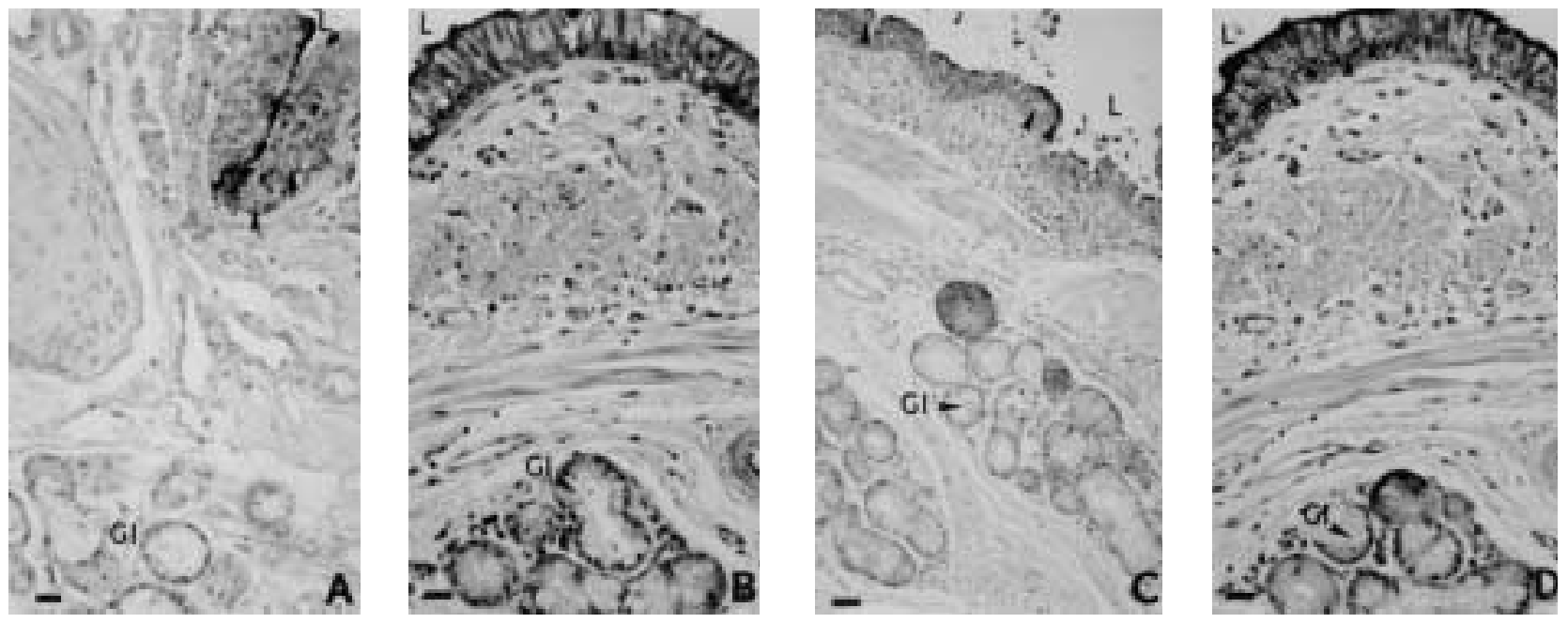

Fig. 2. - Immunohistochemical staining of sections from isolated human bronchial preparations with anti-M1 monoclonal antibodies (Mabs) subsequent to ethyleneglycol-bis-( $\beta$-aminoethylether)-N, N, N', $\mathbf{N}^{\prime}$-tetraacetic acid (EGTA) (0.4 mM) exposure. Only intracellular organelles of goblet cells of the surface epithelium of control bronchial preparations were stained with the PM8 Mabs (A). Similarly in EGTA (0.4 mM)-exposed preparations, intracellular organelles of goblet cells were labelled with 1-13 M1 M1 (B), 21 M1 (C) and PM8 Mabs (D). Internal scale bars $=160 \mu \mathrm{m}$. L: lumen of the airway; Gl: glandular region; arrows: Mabs labelling and/or glands. 


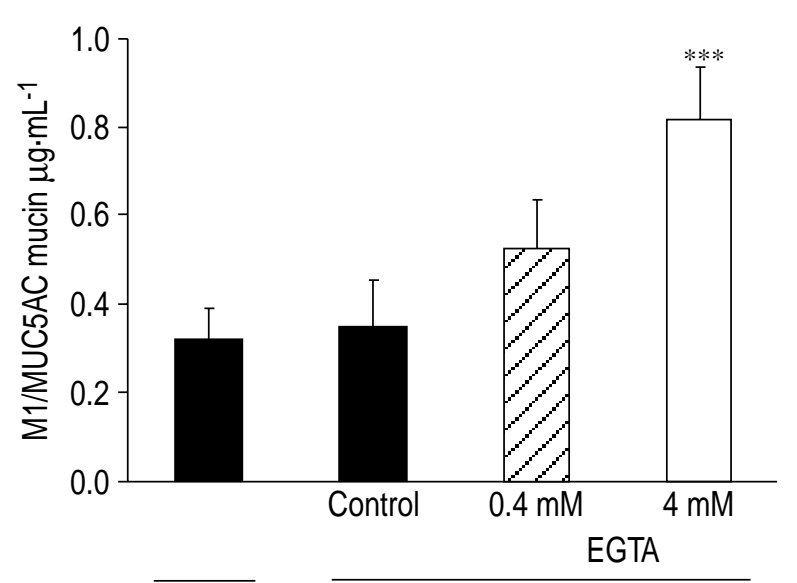

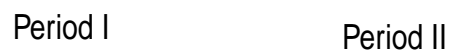

Fig. 3. - Detection of M1/MUC5AC mucin in bronchial fluids derived from isolated human bronchial preparations by immunoradiometric assay using the pooled anti-M1 radiolabelled monoclonal antibodies (Mabs, PM8). Control preparations were performed at Period I (basal release; nine preparations from eight lung samples) and Period II (control; nine preparations from eight lung samples). M1/MUC5AC mucin was determined in fluids after exposure of bronchial preparations to ethyleneglycol-bis- $(\beta$-aminoethylether)-N, N, N', N'-tetraacetic acid (EGTA) $(0.4 \mathrm{mM}$; three preparations from three lung samples) and EGTA $(4 \mathrm{mM} ; 13$ preparations from nine lung samples) Data are presented as mean \pm SEM. $* * *$ : significant difference $(\mathrm{p}<0.001)$ from basal values (Period I).

Treatment of bronchial fluids with ethyleneglycol-bis( $\beta$-aminoethylether)- $N, N, N^{\prime}, N^{\prime}$-tetraacetic acid $4 m M$

When fluids derived from intact control bronchial preparations at Period II were treated with EGTA ( $4 \mathrm{mM} ; 1.38 \pm 0.23 \mathrm{M} 1 / \mathrm{MUC5AC} \operatorname{mucin}\left(\mu \mathrm{g} \cdot \mathrm{mL}^{-1}\right)$; fig. 5), these quantities of M1/MUC5AC mucin, when detected with the PM8 Mabs, were significantly increased compared with either the amounts determined in control bronchial fluids or in fluids treated with EGTA $(0.4 \mathrm{mM} ; 0.36 \pm 0.04 \mathrm{Ml} / \mathrm{MUC5AC}$ mucin $\left(\mu \mathrm{g} \cdot \mathrm{mL}^{-1}\right)$; fig. 5). Furthermore, the quantities of M1/MUC5AC mucin in EGTA (4 mM)-treated bronchial fluids derived from preparations in which the surface epithelium had been removed, were also measured using the individual $21 \mathrm{M} 1 \mathrm{Mab}$. Under these latter conditions, the M1/MUC5AC mucin levels detected were similar $\left(0.83 \pm 0.23 \mu \mathrm{g} \cdot \mathrm{mL}^{-1}\right.$ and $0.73 \pm 0.10 \mu \mathrm{g} \cdot \mathrm{mL}^{-1}$, fluids from control, Period I, and treated, Period II, respectively; $\mathrm{n}=4$ lung samples). When these latter values were compared with those of the PM8 measurements, a ratio of $\sim 2: 1$ for the detection of M1/MUC5AC was observed $(1.38 \pm 0.23$ M1/MUC5AC mucin $\left(\mu \mathrm{g} \cdot \mathrm{mL}^{-1}\right)$ versus $0.73 \pm 0.10$ M1/MUC5AC mucin $\left(\mu \mathrm{g} \cdot \mathrm{mL}^{-1}\right)$, Period II; PM8 and $21 \mathrm{M} 1$, respectively).

\section{Lactate dehydrogenase and protein determination}

LDH release was not significantly modified in bronchial fluids derived from tissues exposed to EGTA (4 mM) when results were compared with
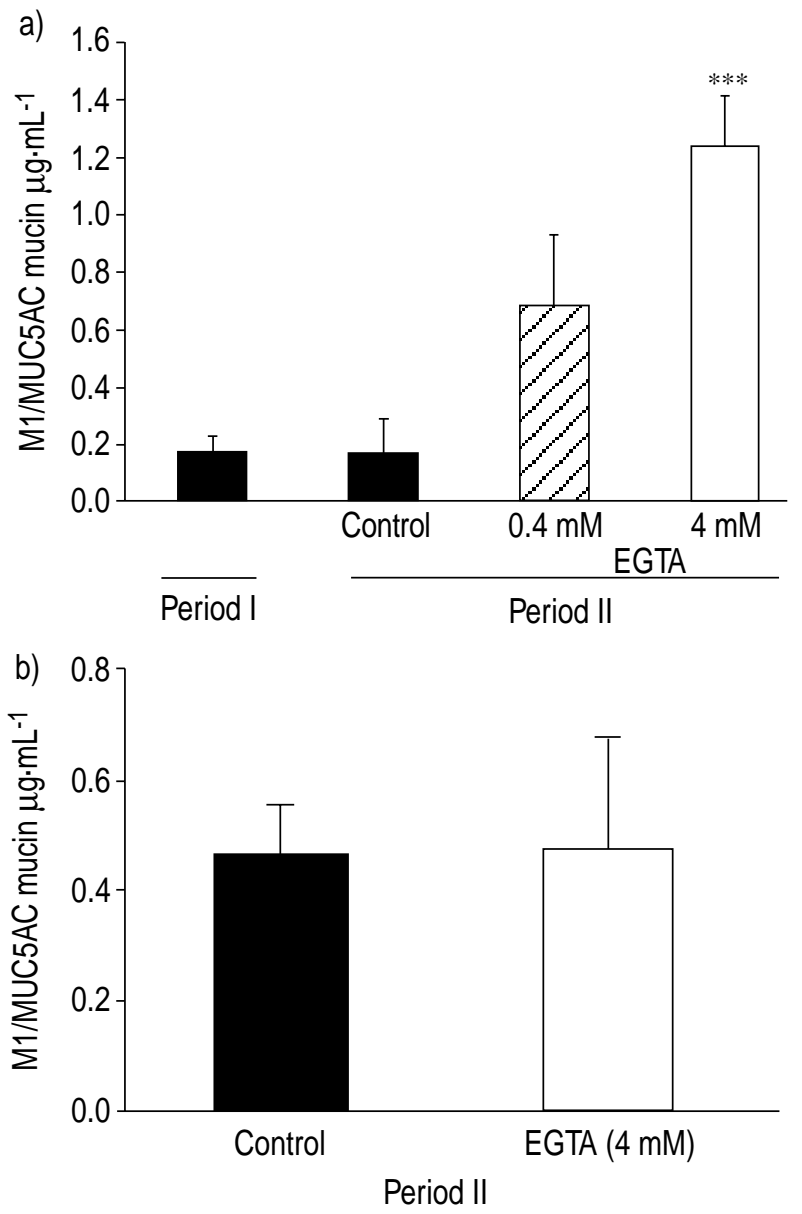

Fig. 4. - a) Determination of the amounts of M1/MUC5AC mucin in bronchial fluids derived from preparations in which the surface epithelium had been removed by immunoradiometric assay using the pooled PM8 radiolabelled monoclonal antibodies (Mabs). Data are presented as mean \pm SEM and were obtained at Period I (basal release; five bronchial preparations from three lung samples) and after exposure of preparations to ethyleneglycolbis-( $\beta$-aminoethylether)- $N, N, N^{\prime}, N^{\prime}$-tetraacetic acid (EGTA) ( $0.4 \mathrm{mM}$; Period II; seven bronchial preparations from three lung samples) and EGTA ( $4 \mathrm{mM}$; Period II; 7 bronchial preparations from 3 lung samples). b) The quantities of M1/MUC5AC mucin detected in fluids obtained at Period II from control (two bronchial preparations from two lung samples) and EGTA (4 mM)exposed bronchial preparations (two bronchial preparations from two lung samples) and detected with the individual 21 M1 Mab. $* * *$ : significant difference $(\mathrm{p}<0.001)$ from basal values (Period I) or paired controls (Period II (b)).

values obtained in control preparations (table 1). In addition, EGTA (4 mM) did not significantly alter the quantities of protein released from bronchial preparations when results were compared with data from paired control preparations (table 1).

\section{Discussion}

Exposure of isolated human airways with an intact surface epithelium to the calcium chelator EGTA $(0.4$ and $4.0 \mathrm{mM}$ ), increased the immunohistochemical tissue detection and the quantities of M1/MUC5AC immunoreactivity in fluids obtained from human 


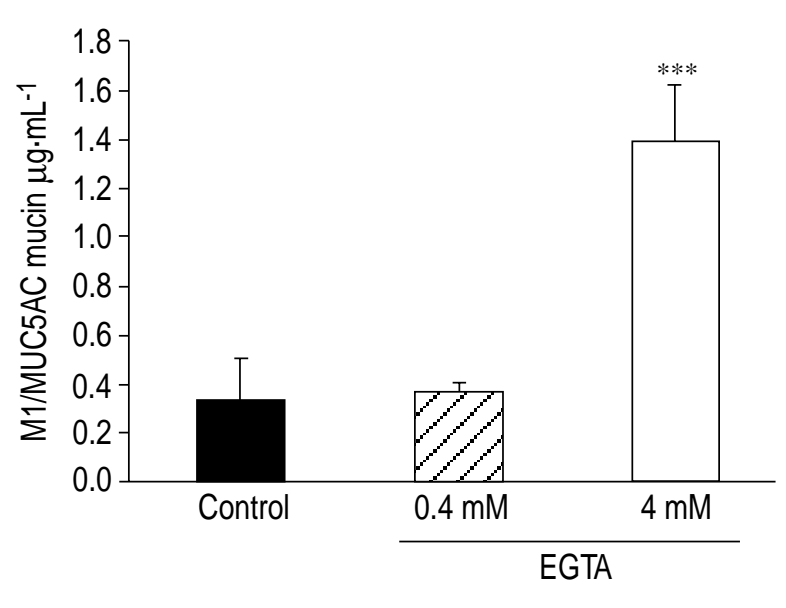

Period II

Fig. 5. - The bronchial fluids derived from control preparations were treated with ethyleneglycol-bis-( $\beta$-aminoethylether)- $\mathrm{N}, \mathrm{N}, \mathrm{N}^{\prime}$, $\mathrm{N}^{\prime}$-tetraacetic acid (EGTA) $(0.4$ and $4 \mathrm{mM})$ and the amounts of M1/MUC5AC mucin were determined by immunoradiometric assay using the pooled PM8 monoclonal antibodies (Mabs). Data are presented as mean \pm SEM and were obtained at Period II (untreated fluids; six bronchial preparations from three lung samples) and subsequent to treatment of bronchial fluids with EGTA (0.4 mM; Period II, six bronchial preparations from three lung samples) and EGTA (4 mM; Period II; 10 bronchial preparations from six lung samples). $* * *$ : significant difference $(\mathrm{p}<0.001)$ from basal values (Period I).

bronchial preparations. In airway preparations, where the surface epithelium has been removed, EGTA $(4 \mathrm{mM})$ exposure also induced an increase in the detected quantities of M1/MUC5AC mucin. These results suggest that M1/MU5CAC mucin may also be present and secreted from the region of the submucosal glands. In addition, EGTA $(4 \mathrm{mM})$ treatment of the bronchial fluids derived from control preparations lead to an enhanced detection of M1/MUC5AC mucin specifically with the pooled Mabs (PM8 Mabs). In contrast, EGTA (4 mM) treatment of bronchial preparations was not associated with the release of either lactate LDH or protein. Together, these observations suggest that EGTA may modify the physicochemical properties of mucin by inducing conformational changes in the mucin glycoprotein. Such a modification

Table 1. - Detection of lactate dehydrogenase (LDH) and protein release in bronchial fluids derived from isolated human bronchial preparations.

\begin{tabular}{lccr}
\hline & Treatment & $\begin{array}{c}\text { LDH } \\
\text { Units } \cdot \mathrm{mL}^{-1}\end{array}$ & $\begin{array}{r}\text { Protein } \\
\mu \mathrm{g} \cdot \mathrm{mL}^{-1}\end{array}$ \\
\hline Period I & Control & $369 \pm 56$ & $104 \pm 15$ \\
Period II & Control & $252 \pm 53$ & $92 \pm 15$ \\
& EGTA (4 mM) & $293 \pm 65$ & $112 \pm 13$ \\
\hline
\end{tabular}

Values are presented as mean \pm SEM of six bronchial preparations from three lung samples. $\mathrm{LDH}$ and protein were determined in bronchial fluids at Period I (basal release) and Period II (60-min exposure to ethyleneglycol-bis-( $\beta$ aminoethylester)-N, N, N', $\mathrm{N}^{\prime}$-tetraacetic acid (EGTA); $4 \mathrm{mM})$. unmasks other epitopes on respiratory mucin to which the different anti-M1 Mabs are reactive, thereby facilitating the detection of this glycoprotein in human airways.

BARA et al. [9] reported immunohistochemical data demonstrating that a variety of anti-M1 Mabs which reacted with the gastric M1 mucin also labelled tissues from the human respiratory tract. These investigators demonstrated that individual 1-13 M1, 9-13 M1 and 58 M1 Mabs reacted with the epithelial surface of human airway and also exhibited a faint labelling in the submucosal glandular region. These initial observations were supported by recent studies, which showed that goblet cells of the surface epithelium were stained by the 1-13 M1 and 21 M1 Mabs in unstimulated human bronchial preparations [12] as well as in EGTA $(0.4 \mathrm{mM})$-exposed preparations (present report). These latter results demonstrated that the M1/MUC5AC mucin was principally detected in the goblet cells of bronchial tissues and was not derived from the submucosal glandular region, since the $21 \mathrm{M} 1 \mathrm{Mab}$ failed to label this area even after EGTA treatment (figs. 1 and 2). These data are in agreement with a previous report by LABAT et al. [12]. However, the present data also showed that in bronchial preparations exposed to EGTA (4 mM), mucin contained in the submucosal glands was stained with the 1-13 M1 Mab and PM8 Mabs, suggesting that EGTA exposure of tissues unmasked other epitopes of mucin in the submucosal glands to which anti-M1 Mabs are specifically reactive. However, in EGTA (4 mM)-exposed bronchial tissues, glands were not labelled with the individual 21 M1 Mab, while staining was observed in the goblet cells (present report). In contrast, M1/MUC5AC mucin was detected by IRMA in bronchial fluids derived from EGTA-exposed preparations, these latter results suggest that there may be differences between the two techniques for the detection of mucin. Several possible explanations for these differences can be proposed. Firstly, there may be a greater access to the epitope for the $21 \mathrm{M} 1 \mathrm{Mab}$ when the respiratory mucins are in solution, whereas in labelling of tissues, only a limited number of sites may be exposed. However, a correlation between tissue fixation of Mabs and the detection of mucins by IRMA has not yet been established and further experiments are required to examine why these differences for detection exist. Secondly, EGTA may interfere with the enzymatic formation of mucin and thereby unmask epitopes. The glycosylation of the M1/MUC5AC in the submucosal glands may be different from that of the epithelium and therefore, mask the $21 \mathrm{M} 1$ epitope. BARA et al. [18] have already shown such an occulting phenomenon for the MUC-1 PDTRP epitope (main epitope in the tandem repeat domain of the MUC-1 protein core) in the gastric mucosa.

CoLEs and coworkers [2, 5] previously demonstrated that the baseline release of mucin glycoprotein from canine tracheal explants or epithelial cells was increased in the presence of EGTA and proportional to the concentration of the chelator. These investigators [2] reported that removal of surface epithelium from tracheal explants subsequent to exposure to 
EGTA (4 mM) modified the secretory response, suggesting that the enhanced release of mucins was principally from the submucosal glands in $\mathrm{Ca}^{2+}$ and $\mathrm{Mg}^{2+}$-free media. In EGTA (4 mM)-exposed intact bronchial tissues in the present report, approximately a two-fold increase in detection above basal levels of M1/MUC5AC mucin was observed. In addition, in bronchial preparations devoid of a surface epithelium, the EGTA $(4 \mathrm{mM})$ treatment caused approximately a six-fold increase above basal levels (Period II, control). There was also a significant increase in the amounts of M1/MUC5AC mucin detected in the EGTA (4 mM)-treated bronchial fluids derived from denuded bronchial preparations when compared with controls. Together, these data support the notion that M1/MUC5AC mucin was in part derived from the submucosal glands under these experimental conditions. A number of investigations [19-22] have demonstrated that glands are generally associated with MUC5B, whereas MUC5AC is found in the goblet cells of the surface epithelium [12]. However, AudiE et al. [23] have shown that in the human lung, the submucosal glands express the MUC5AC gene; the results of EGTA treatment may provide an interesting technique for unmasking the presence of the MUC5AC mucin in human airways during functional studies. Interestingly, LABAT et al. [12] showed that detection of M1/MUC5AC mucin by PM8 Mabs in bronchial tissues was $\sim 10$-fold higher than detection with the $21 \mathrm{M} 1 \mathrm{Mab}$. In contrast, the ratio of $\mathrm{M} 1 / \mathrm{MUC5AC}$ mucin detected by the PM8 Mabs versus $21 \mathrm{M} 1 \mathrm{Mab}$ in the present report, was $\sim 2: 1$ following the EGTA treatment. This observation indirectly supports the suggestion that a conformational change in the respiratory mucin has occurred, thereby exposing other epitopes to which the Mabs are directed. These data support the results of previous studies demonstrating that EGTA caused marked dissociation of mucin complexes with alteration in viscosity [7]. Since calcium concentrations in secretions derived from patients with cystic fibrosis have been reported to be elevated [24], EGTA treatment of mucus from these subjects may facilitate the solubilization and/or dilution of such samples during clinical studies involving biochemical analyses.

Previous studies [5, 25, 26] have reported that epithelial exfoliation of airway preparations as a consequence of incubation in $\mathrm{Ca}^{2+}$-free media containing ion chelators, may be responsible for the increased detection of glycoproteins. However, the presented data suggest that this phenomenon may not be involved since: 1) the optical microscopic observations of sections of EGTA $(4 \mathrm{mM})$-incubated tissues did not reveal any damage to the epithelial or submucosal layers; and 2) no increase in the release of either $\mathrm{LDH}$ or protein was observed in the bronchial fluids derived from EGTA-challenged bronchial preparations compared with controls.

In conclusion, the data reported in the present study suggest that ethyleneglycol-bis-( $\beta$-aminoethylether)$\mathrm{N}, \mathrm{N}, \mathrm{N}^{\prime}, \mathrm{N}^{\prime}$-tetraacetic acid $(4 \mathrm{mM})$ may unmask sites on respiratory mucin, thereby exposing other epitopes with which the anti-M1 monoclonal antibodies are reactive. These unmasked epitopes are found on mucin which is derived from the bronchial submucosal glands of human airways.

Acknowledgements. The authors would like to thank S. Fatal, in the laboratory of biochemistry of the Centre Chirurgical Marie Lannelongue, for his excellent technical assistance.

\section{References}

1. Marin MG, Estep JA, Zorn JP. Effect of calcium on sulfated mucous glycoprotein secretion in dog trachea. J Appl Physiol: Respirat Environ Exercise Physiol 1982; 52: $198-205$.

2. Coles SJ, Bhaskar KR, O'Sullivan DD, Reid LM. Extracellular calcium ion depletion induces release of glycoproteins by canine trachea. Am J Physiol (Cell Physiol) 1984; 15: C494-C501.

3. Kim KC, Zheng QX, Brody JS. Effect of floating a gel matrix on mucin release in cultured airway epithelial cells. J Cell Physiol 1993; 156: 480-486.

4. Balfre K. The effects of calcium and calcium ionophore A23187 on mucin secretion and potential difference in the isolated chicken trachea. J Physiol 1978; 275: $80 \mathrm{P}-81 \mathrm{P}$.

5. Coles SJ, Judge J, Reid L. Differential effects of calcium ions on glycoconjugate secretion by canine tracheal explants. Chest 1982; 81: 34S-36S.

6. Mian N, Kent PW. Directional $\mathrm{Ca}^{2+}$ effect on stimulation of mucin secretion from chicken trachea in vitro. Biochem J 1982; 208: 425-433.

7. Mian N, Kent PW. Role of directional $\mathrm{Ca}^{2+}$ effect on stimulation of common mucins and unique sulfate-rich components from chicken trachea in vitro. Biochim Biophys Acta 1986; 883: 476-485.

8. Forstner JF, Forstner GG. Effects of calcium on intestinal mucin: implications for cystic fibrosis. Pediat Res 1976; 10: 609-613.

9. Bara J, Gautier R, Daher N, Zaghouani H, Decaens C. Monoclonal antibodies against oncofetal mucin M1 antigens associated with precancerous colonic mucosae. Cancer Res 1986; 46: 3983-3989.

10. Bara J, Gautier R, Mouradian P, Decaens C, Daher $\mathrm{N}$. Oncofetal mucin M1 epitope family: characterization and expression during colonic carcinogenesis. Int J Cancer 1991; 47: 304-310.

11. Bara J, Chastre E, Mahiou J, et al. Gastric M1 mucin, an early oncofetal marker of colon carcinogenesis, is encoded by the MUC5AC gene. Int J Cancer 1998; 75: $767-773$.

12. Labat C, Bara J, Gascard JP, et al. M1/MUC5AC mucin released by human airways in vitro. Eur Respir $J$ 1999; 14: 390-395.

13. Roger P, Gascard JP, Bara J, Brink C. Development of a functional human bronchial model of mucin secretion. Therapie 2000; 55: 51-54.

14. Roger P, Gascard JP, Bara J, de Montpreville VT, Yeadon M, Brink C. ATP induced MUC5AC release from human airways in vitro. Mediators of Inflammation 2000; 9: 277-284.

15. Van den Ingh HF, Bara J, Cornelisse CJ, Nap M. Aneuploidy and expression of gastric-associated mucus 
antigens M1 and CEA in colorectal adenomas. Am $J$ Clin Pathol 1987; 87: 174-179.

16. Bara J, Gautier R, Le Pendu J, Oriol R. Immunochemical characterization of mucins: polypeptides (M1) and polysaccharide (A and Lewis) antigens. Biochem J 1988; 254: 185-193.

17. Lowry OH, Rosebrough NJ, Farr AL, Randall RJ. Protein measurement with the Folin Phenol reagent. J Biol Chem 1951; 193: 265-275.

18. Bara J, Imberty A, Perez S, Imai K, Yachi A, Oriol R. A fucose residue can mask the MUC-1 epitopes in normal and cancerous gastric mucosae. Int $J$ Cancer 1993; 54: $607-613$.

19. Hovenberg HW, Davies JR, Herrmann A, Linden CJ, Carlstedt I. MUC5AC, but not MUC2, is a prominent mucin in respiratory secretions. Glycoconj $J$ 1996; 13 : $839-847$.

20. Reid CJ, Gould S, Harris A. Developmental expression of mucin genes in the human respiratory tract. Am J Respir Cell Mol Biol 1997; 17: 592-598.

21. Sharma P, Dudus L, Nielsen PA, et al. MUC5B and MUC7 are differentially expressed in mucous and serous cells of submucosal glands in human bronchial airways. Am J Respir Cell Mol Biol 1998; 19: $30-$ 37.

22. Buisine MP, Devisme L, Copin MC, et al. Developmental mucin gene expression in the human respiratory tract. Am J Respir Cell Mol Biol 1999; 20: $209-$ 218.

23. Audie JP, Janin A, Porchet N, Copin MC, Gosselin B, Aubert JP. Expression of human mucin genes in respiratory, digestive and reproductive tracts ascertained by in situ hybridization. J Histochem Cytochem 1993; 41: $1479-1485$.

24. Gibson EC, Mathews WJ, Minihan PT, Patti JA. Relating mucous, calcium and sweat in a new concept of cystic fibrosis. Pediatrics 1971; 48: 695-710.

25. Scaletta LJ, MacCallum DK. A fine structural study of divalent cation-mediated epithelial union with connective tissue in human oral mucosa. Am J Anat 1972; 133: $431-454$.

26. Tandler B, Sherman J, Boat TF. EDTA-mediated separation of cat tracheal lining epithelium. Am Rev Respir Dis 1981; 124: 469-475. 